\title{
Research on the Reform and Practice of English Listening Teaching for Application-guided Universities
}

\author{
Peng Qian \\ Wuhan Donghu University, \\ Wuhan,Hubei,China
}

\begin{abstract}
In this paper, we conduct research on the reform and practice of English listening teaching for the application-guided universities. In the recent years at home and abroad for a lot of work on listening teaching, has made some breakthrough. Through the study of literature, however, we found that compared with the listening teaching research abroad, our country most of the research is descriptive, intervention studies is less, so the study should be further expand the breadth and depth. Under this background and the concepts of the application-guided universities, we propose the novel English listening teaching paradigm for teachers. We want to be in fully draw lessons from the foreign advanced listening teaching on the basis of theory, model, combined with the actual teaching situation in our country development suited to China's foreign language classroom listening teaching methods.
\end{abstract}

Keywords- Reform and Practice, English Listening, Teaching, Application-guided, Colleges.

\section{Introduction}

With the improvement of the social requirements for foreign language talents, people pay more and more attention to the language as a means of the communication and people from different cultural backgrounds communicate and access to information, for all kinds of communicative activities. Our English teaching will conform to the trend of the times through the teaching reform.

Traditional language practice is one of the biggest disadvantages from context, from the function, the students can know different language form, but not in the form correctly express meaning and the function. Form functional principle is on the basis of principle of authenticity, it will clearly identify the relationship between language form and function, let the student feel fully in the task performance in the relationship between language form and function, and the relationship between language and the context that enhance students understanding of the appropriateness of language use and language communication. According to the literature review, the state-of-the-art teaching methodologies could be generally summarized as the follows. (1) Cognitive method. Cognitive method against language is "structural model" theory, the opposition in the teaching of mechanical operation practice over and over again. It argues that language is the creative activity governed by rules of habit is master rules, rather than the form habits that advocate using deductive method to teach grammar. (2) Function of communicative approach. In the process of this kind of communicative teaching, practice activity is not only students' initiative that is also one of the social factors that affect the practice of the discourse, because students subjective thoughts, attitudes, emotion, culture can also affect choice of language form and language function. (3) Audio-visual method. Audio-visual method than just rely on auditory or visual to understanding, memory and storage of the language material. The conditions of the visual image for the students thinking in images, prompting students to natural and firmly grasp a foreign language. (4) The direct method. The direct method is living language teaching, especially in training oral English ability, significant achievements. Direct method compared with the classical grammar translation method is a big step forward in teaching history, become after heard method, audio-visual method, 
function method and other modern reformist originated [1-3].

Applied mainly refers to in the process of to cultivate talent, the focus is not on the theory of the teaching, but to teach students how to apply the theoretical knowledge in the process of actual work or life, by this method, cultivate the students also known as the applied talents. It has the ability to solve problems independently, and innovative thinking ability is stronger, at the same time with a high level of learning ability that is a kind of the talents. Shift the focus of the management system of an applied university, shift the focus to the students work, work actively, reduce the management methods in the process of management work more active communication with students. At the same time, actively promote student autonomy of work, enhance the students' self-management ability as further improve their practice ability. Accordingly, figure one shows the keywords of the English listening teaching.

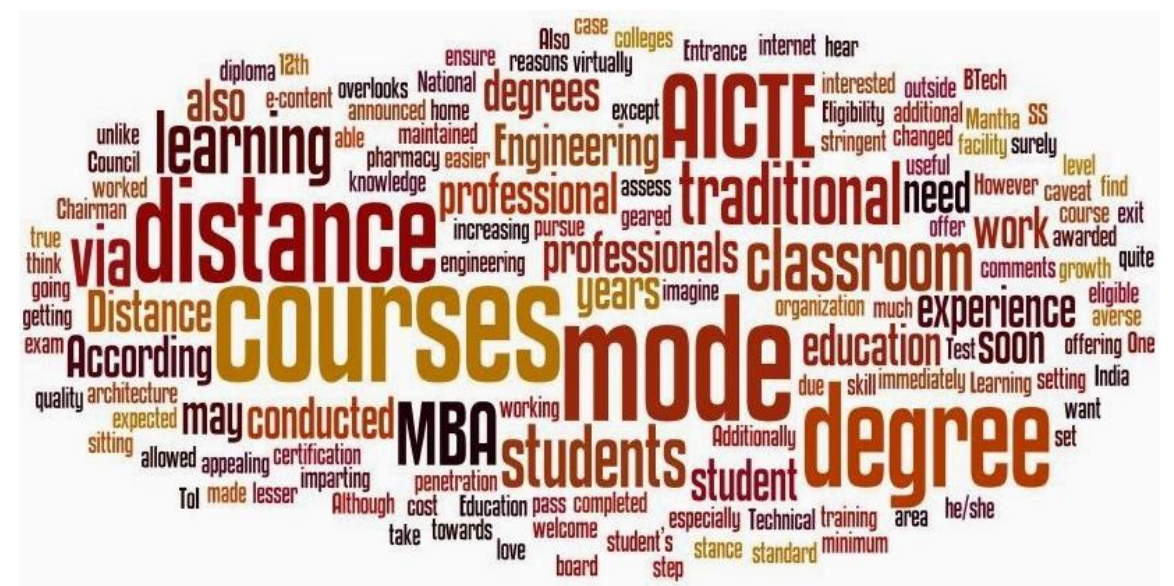

Figure 1. The Keywords of the English Listening Teaching

In this paper, we conduct research on the reform and practice of English listening teaching for the application-guided universities. Applied undergraduate education in the school-running orientation, personnel training goal and professional set etc. are prominent features of cultivating the ability of the application. Construction of the new curriculum standard, to attain the goal of national education and the target of talent training, talent of education high quality plays an important role. In the following sections, we will combine the concepts to put forward our unique methodology.

\section{The Proposed Methodology}

The Features of the Application-Guided Universities. Applied university is a novel product of the popularization of higher education, which is different from university of a new type of the research university, its concept is broad, it not only include university of applied technology, also includes a service-oriented university, university of the technology, service-oriented entrepreneurial university, teaching model and teaching university, etc.

In college education system itself, but also with the actual situation of social development and needs, timely adjustment of development patterns, therefore, our country existing university basically self-analysis and layered, part to become a research school, part of model was applied development. Many colleges and universities and scholars also applied talents training mode and quality evaluation system and related topics of research and practice. Applied university is to cultivate the undergraduate students, is the vocational education of undergraduate course education is given priority to liquid. In today's society and university of 
checks and balances economic development situation, to the university to develop applied university is really not easy. In the process of development of applied undergraduate colleges and universities must solve practical problems and logically. As for general construction of the application-guided universities, we should follow the listed issues [4-5].

- Based on the ability to adjust the course content. In general, applied when making the scheme of talent cultivation in colleges and universities, notice from the post capacity requirements, formulate training plan. But in the design of the curriculum content, not only from a certain position requirements or vocational requirement, also give full consideration to the industrial chain of jobs in the group of common requirements and composite capacity requirements.

- According to the needs of society set curriculum goals. In the process of talent training, can not only adapt to the career goal, also should emphasize the adaptability of students for jobs, in era of entrepreneurship, innovation, entrepreneurship education should strengthen innovation.

- Pay attention to teaching quality guarantee system. As part of the quality monitoring system of colleges and universities in our country is not perfect or not there is a strict and the effective operation of the phenomenon, therefore, we need to pay more attention to the problems of the teaching quality guarantee system.

The English Listening Ability. From the perspective of the law of the language acquisition, any language, spoken language is first, grammar is the second text. Language learning begins with the listening. At present, with the deepening of the reform and opening up and the increase in the foreign exchange activity, hearing more and more important in the position in language learning. In process of the implementation of classroom listening teaching, the teachers should consciously to students for a variety of conventional type training, and cultivate students form good listening habits. The primary training suggestions for listening ability enhancement could be organized as follows.

- To guide the training. In the notice on the processing of the design of the different text types, according to these questions to guide students fine listens with pan-listens, so that the students can not only complete in the process of the listening the preliminary understanding of the text meaning, and to seize the details [6].

- Speculation and reasoning ability training. The listener can not only according to the speaker and the relationship between the prediction speech sound, as can also according to the speech, occasions, such as to determine the identity of the speaker, and concluded that its views.

- Training and imitation training again and again. Each phoneme, syllables, words, sentences in English are not exist in isolation, the listener need to combine their knowledge of vocabulary and grammar have heard information in a particular meaning.

Teachers should make full use of the multimedia teaching in English listening teaching equipment, prepare related courseware, audio, video, data, etc. to enrich the English listening class, improve the students' enthusiasm and initiative overcomes the student to study the tension and anxiety. In addition, the teacher can also adopt the method of positive questions, causes the student to participate in class activities, active classroom atmosphere, and eventually to improve student English listening learning efficiency. In the following figure we demonstrate the mentioned principles. 


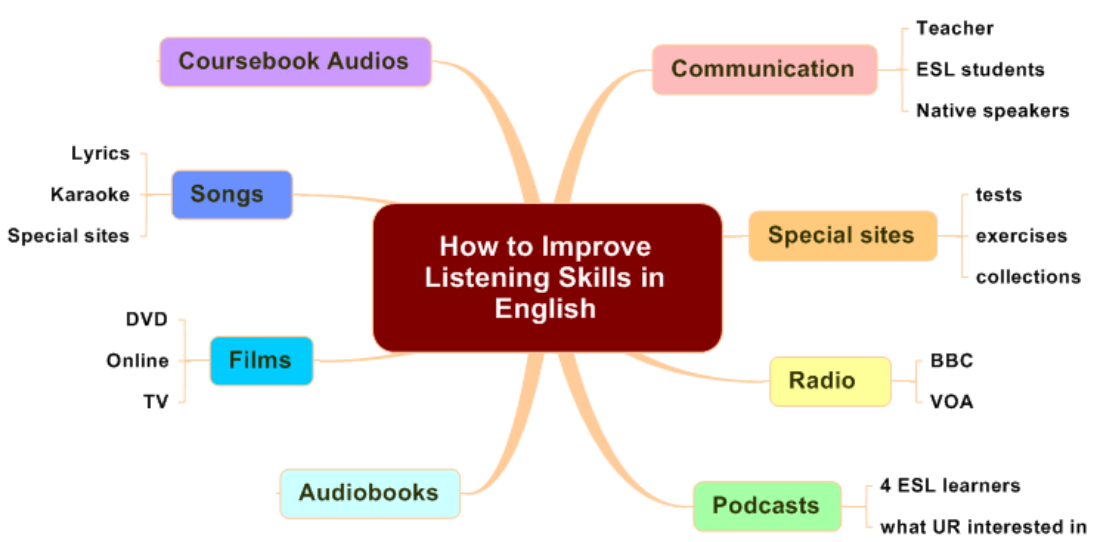

Figure 2. The Approaches for the English Listening Ability Enhancement

The English Teaching Methodology. When it comes to foreign language learning, Nuttall said a sentence: the best way to improve language training is to use the language in people life, followed by the extensive reading. English language teaching at home and the abroad of various schools from the different teaching objectives, teaching conditions and different psychological principle or linguistic theory, respectively, puts forward some teaching principles. These principles are reflected to a range of practical experience that has certain guiding significance for English teaching [7].

Verbal ability of using language is comprehensive. In English teaching to cultivate students' verbal ability of materials should also has the characteristics of comprehensive. Because the reading training, especially the intensive reading and reading is a key part of the training text teaching, leaving the text teaching is hard to talk about what a strict reading training. The cultivation of reading ability through reading a sufficient number of the materials and implementation, in the school teaching is to read a number of texts and supplementary readings. Grammar class, its starting point is based on the inherent law of language itself in the first place to cultivate students practical ability of using language, spend less power, reap big effect. Is the general trend of English teaching at present, the various schools of the grammar to useful things eclectic teaching with the arrangement of the teaching material of both traditional grammar, functional grammar and general communication.

In the teaching is given priority to with heard, heard that lead, which is according to the natural shape of the language to English teaching, and not just in order to develop the ability of listening and the speaking. Technician training target is reading, must also be a large number of heard that training, insisted on leading heard can truly give students reading ability. Directly from the teaching point of the view, the development of thinking ability is also gradually, is relative, not absolute. As long as pay attention to the training, teaching methodology, so to make the students within the scope of what they have learned at a certain level of thinking directly, it is possible. Due to the direct thinking ability is an ability to use English translation, so, in order to effectively cultivate the ability to properly limit the use of translation methods in the teaching.

The Reform and Practice of English Listening Teaching. Listening is not only an important language learning skills, or other important means of language ability. Listening and reading skills belong to the receptive skills, in the process of listening teaching as can draw lessons from discourse analysis method in the process of reading, thus more in-depth more scientifically guide the student to obtain language communicative competence. In the teaching English listening teaching occupies an extremely important position, it to cultivation of college students' English comprehensive application 
ability, improve the comprehensive cultural quality has a very important role. To improve students' English comprehensive applied ability has become the main goal of the English teaching in China. Through the understanding of the listening teaching research status at home and abroad, we can draw lessons from advanced experience and learning, the English listening teaching in China is of great realistic significance that should follow the listed suggestions and countermeasures [8].

- Select proper listening material. The difficulty of the material must be suitable for the students' current level of difficulty for flexibility, or otherwise will directly kill students' confidence and interest in the hearing. Material should be diversified. Provide students a variety of listening materials, combined with the students of class time pan-listens can be fully realized.

- Progressive teaching plan. The traditional listening teaching does not emphasize importance of the four learning during the teaching plan, largely confined to finish the listening textbook several units in listening and practice, timely if possible to add some extracurricular materials related to textbook content.

- Teacher teaching model of shift. Teachers in addition to provide students with the necessary background knowledge, basic language knowledge, but also and the student together into the hearing training, pay attention to listen to the individual student's answers and explanations.

- Listening exercises set to be targeted. Hearing the teacher should be aimed at training content design effective form of the practice, it can not only stimulate students' interest in the learning, virtually also teach students all aspects of the listening skills, and to encourage students to use their mastery of the listening skills to solve the problem.

\section{Conclusion}

In this paper, we conduct research on the reform and practice of English listening teaching for the application-guided universities. Traditional listening comprehension teaching often emphasizes on the training of the language itself, ignore the import of cultural content. As the importance of culture in the language acquisition, English listening teachers fully realize that the right understanding of the language cannot do without the support of cultural background knowledge in classroom teaching, the teacher not only to help students to solve the obstacle of the language and skills, but also consciously cultural import. Our research proposes the novel paradigm for the corresponding challenges that is innovative and in the recent future we will focus on the integration of the cultural education for the further optimization of the proposed methodology.

\section{Acknowledgement}

This paper is financially supported by the 2015 school level research project in the Wuhan Donghu University. The corresponding project name is: Reform and practice of English listening teaching in application-guided universities.

\section{Reference}

[1] Kun, Yang, Jiang Canzhong, and Liu Jiewei. "Frame Theory and Its Application to Discourse-based English Listening Teaching." International Research in Education 3.1 (2015): 54-64.

[2] Zheng, Chuanlin, et al. "An Empirical Study of Teaching Narrow Listening in College English." International Proceedings of Economics Development and Research 70 (2014): 96.

[3] Jun, T. A. N. G. "Research on Autonomous Learning Strategies of College English 
Listening." Journal of Jilin Institute of Chemical Technology 4 (2013): 011.

[4] Dan, X. U. "On the Use of English Songs to Listening Course from the Perspective of Cognitive Psychology [J]." Journal of Chengdu Normal University 1 (2013): 021.

[5] DiCerbo, Patricia A., et al. "A review of the literature on teaching academic English to English language learners." Review of Educational Research 84.3 (2014): 446-482.

[6] De Brito, Juary. "The Effects of Listening Comprehension on English Language
Learners Writing Performance while Taking Notes." (2015).

[7] Xuan, Xu. "An Inquiry into the Listening and Speaking Teaching Strategies for English Majors in the" Post-method" Era." The Science Education Article Collects 12 (2013): 075.

[8] Rahimirad, Maryam, and Abbas Zare-ee. "Metacognitive Strategy Instruction as a Means to Improve Listening Self-Efficacy among Iranian Undergraduate Learners of English." International Journal of Instruction 8.1 (2015): 117. 